\title{
Risk Assessment for Propane Cooler in Natural Gas Liquefaction Plant
}

\author{
Khaled Habib Ezzat, Yassmine Ossaama, Nevine Kamal, Hassan Farag \\ Faculty of Engineering, Alexandria University, Alexandria, Egypt \\ Email: ofowan5@hotmail.com
}

Received 5 March 2015; accepted 27 June 2015; published 30 June 2015

Copyright (C) 2015 by authors and Scientific Research Publishing Inc.

This work is licensed under the Creative Commons Attribution International License (CC BY). http://creativecommons.org/licenses/by/4.0/

c) (i) Open Access

\begin{abstract}
Natural Gas Transportation requires Natural Gas to be in its Liquid state, liquefying Natural Gas requires decreasing temperature to a very low level. This requires severe temperature and pressure conditions. This paper will discuss a risk assessment study on a Node in the plant of Natural Gas, which is the propane heat exchanging unit, which decreases the temperature of the flow gradually at the beginning to remove heavy liquids. Risk assessment study is applied using three methods, HAZOP, DMRA and LOPA.
\end{abstract}

\section{Keywords}

HAZOP, LOPA, Risk Assessment, DMRA, Natural Gas Liquefaction, Propane

\section{Introduction}

Risk analysis is a systematic effort to quantify uncertainties associated with undesirable events [1]. Although Natural Gas is of an important value to economic and domestic use, it is still one of the most dangerous industries that must be dealt safely with great care [2].

HAZOP is one of the most used methods worldwide, when Risk assessment is applied to a Natural Gas Liquefaction unit [3]. It categorizes the events in the plant according to the risk it possess [3]. HAZOP can be applied t nearly every portion of Natural Gas Liquefaction unit [4] although HAZOP is of high importance. It is still a quantitative method, which means it does not quantifies the risk into numbers. This is why it is tagged with DMRA (Decision Matrix Risk Assessment) which transforms the outcomes of the HAZOP study into numerical values.

The Layer of Protection Analysis (LOPA) method is a Process Hazard Analysis tool. The method utilizes the hazardous events, event severity, initiating causes and initiating likelihood data developed during the Hazard and Operability analysis (HAZOP).

How to cite this paper: Ezzat, K.H., Ossaama, Y., Kamal, N. and Farag, H. (2015) Risk Assessment for Propane Cooler in Natural Gas Liquefaction Plant. Advances in Chemical Engineering and Science, 5, 270-281.

http://dx.doi.org/10.4236/aces.2015.53027 
The LOPA method allows the user to determine the risk associated with the various hazardous events by utilizing their severity and the likelihood of the events being initiated.

This paper discusses the application of the three of the methods on a Natural Gas pre-liquefaction unit.

\section{Risk Assessment Methods}

\subsection{HAZOP}

A Hazard and Operability (HAZOP) study is a structured and systematic examination of a planned or existing process or operation in order to identify and evaluate potential hazards and operability problems or to ensure the ability of equipments in accordance with the design intent. The HAZOP analysis technique uses a systematic process to identify possible deviations from normal operations and ensure that appropriate safeguards are in place to help prevent accidents. It uses special adjectives combined with process conditions to systematically consider all credible deviations from normal conditions. The adjectives, called guide words, are a unique feature of HAZOP analysis [5].

the main characteristics of HAZOP study are 1) A systematic, highly structured assessment relying on HAZOP guide words and team brainstorming to generate a comprehensive review and ensure that appropriate safeguards against accidents are in place. 2) Typically performed by a multidisciplinary team. 3) Applicable to any system or procedure. 4) Generates primarily qualitative results, although some basic quantification is possible [5].

\subsubsection{Advantages}

- The HAZOP process is a systematic examination.

- The team approach to a HAZOP makes it a multidisciplinary study.

- The HAZOP team utilizes operational experience.

- The process covers safety as well as operational aspects.

- Solutions to the problems identified may be indicated.

- HAZOPs consider operational procedures.

- HAZOPs cover human errors.

- The HAZOP study led by independent person.

- HAZOP study results are recorded.

- For team members the process is easily learned and performed.

- A HAZOP does not require considerable technical expertise for technique formulation.

- As a systematic process it provides rigor for focusing on system elements and hazards.

- The HAZOP process is a team effort with many viewpoints [6].

\subsubsection{Limitations}

- A HAZOP focuses on single events rather than combinations of possible events.

- The HAZOP focus on guide-words allows it to overlook some hazards not related to a guide-word.

- Training is essential for optimum results, especially for the facilitator.

- HAZOPs are typically very time consuming and thus expensive [6].

\subsubsection{Guide Tables}

The guide words are the tools that are used to systematically direct the HAZOP study. They are words or phrases that, when considered together with a parameter, form a hypothetical deviation for the team to consider. The basic guide words and phrases are defined as Figure 1.

\subsection{Decision Matrix Risk Assessment (DMRA)}

It is a systematic approach for estimating risks, which is consisting of measuring and categorizing risks on an informed judgment basis as to both probability and consequence and as to relative importance. The combination of a consequence/ severity and likelihood range, gives us an estimate of risk (or a risk ranking). More specifically, the product of severity (S) and likelihood (P) provides a measure of risk (R) which is expressed by the relation: [7]. 


\begin{tabular}{|c|c|}
\hline GUIDE WORD & MEANING \\
\hline NO & $\begin{array}{l}\text { Negation of the design intent (e.g., no flow when } \\
\text { there should be; no pressure when there should be }\end{array}$ \\
\hline LESS & $\begin{array}{l}\text { Less of a physical property than there should be } \\
\text { qualitative decrease (e.g., lower flow rate } \\
\text { than there should be) }\end{array}$ \\
\hline MORE & $\begin{array}{l}\text { More of a physical property than there should be } \\
\text { - qualitative increase }\end{array}$ \\
\hline PART OF & $\begin{array}{l}\text { Composition of the system (stream) is different } \\
\text { than it should be-qualitative decrease (e.g., } \\
\text { less of one component) }\end{array}$ \\
\hline AS WELL AS & $\begin{array}{l}\text { More components present than there should be } \\
\text {-qualitative increase (e.g., extra phase or } \\
\text { impurities present) }\end{array}$ \\
\hline REVERSE & $\begin{array}{l}\text { Logical opposite of the design intent (e.g., } \\
\text { reverse flow) }\end{array}$ \\
\hline OTHER THAN & $\begin{array}{l}\text { Complete substitution (e.g., transfer of a } \\
\text { material other than the material intended; } \\
\text { transfer of a material to a location other than } \\
\text { intended) }\end{array}$ \\
\hline
\end{tabular}

Figure 1. Guide words for a HAZOP study.

$$
R=S \times P
$$

Once the hazards have been identified, the question of assigning severity and probability ratings must be addressed. Eventually, the technique is consummated by the construction of the risk matrix and the decision-making table. The new developed DMRA technique has two key advantages:

a) It differentiates relative risks to facilitate decision-making.

b) It improves the consistency and basis of decision

Risk can be calculated from the above formula, by knowing the values of the probability and Severity of the occasion through the following matrix: [7].

\subsubsection{Six Point Scheme for Hazard Severity Levels \\ -EXTREEMLY HIGH:}

Multiple employee fatalities,

Public fatalities and injuries,

Extensive property damage,

Major environmental impact,

Major adverse public reaction.

-VERY HIGH:

Employee fatalities,

Public injuries,

Significant property damage,

Significant environmental impact,

Adverse public reaction.

-HIGH

Employee injuries medium,

Public injuries medium,

Moderate property damage,

Slightly higher than average environmental impact,

Slightly higher than average public reaction.

-MEDIUM:

Employee injuries minor, 
Public injuries low,

Slightly lower than average property damage,

Moderate environmental impact,

Moderately adverse public reaction.

-LOW:

Minor employee injuries,

No public injuries,

Minor property damage,

Minor environmental impact,

No adverse public reaction.

-INSIGNIFICANT:

Operational upset,

No employee injuries,

No public injuries,

No property damage,

No environmental impact,

No adverse public reaction.

\subsubsection{Probability Ranking}

The probability of an occasion can be ranked according to its chance of occurring. Estimating a probability-unlike the Severity of an occasion-has no stable reference, it is a $100 \%$ brainstorming method using hypothetical scenarios that has the occasion as an outcome. However, it may depend on the number of equipments involved in the scenario, history of similar occasions, or logical thinking of the steps of the scenario [8].

\subsubsection{Risk Ranking}

The ranking of a risk depends on the value of the estimated probability and severity according to the equation:

$$
R=P \times S
$$

The outcome can then be categorized according to its value, which gives an estimated reference to the priority of risks to figure out suggested ways to deal with as mentioned in Figure 2.

\begin{tabular}{|c|c|c|c|c|c|c|}
\cline { 2 - 8 } \multicolumn{1}{c|}{} & \multicolumn{6}{c|}{ Hazard probability ratings } \\
\hline \multicolumn{1}{c|}{} & & & & & & \\
\hline $\begin{array}{c}\text { Severity } \\
\text { of } \\
\text { consequences } \\
\text { ratings } \\
\text { (S) }\end{array}$ & 6 & 5 & 4 & 3 & 2 & 1 \\
\hline 6 & 36 & 30 & 24 & 18 & 12 & 6 \\
\hline 5 & 30 & 25 & 20 & 15 & 10 & 5 \\
\hline 4 & 24 & 20 & 16 & 12 & 8 & 4 \\
\hline 3 & 18 & 15 & 12 & 9 & 6 & 3 \\
\hline 2 & 12 & 10 & 8 & 6 & 4 & 2 \\
\hline 1 & 6 & 5 & 4 & 3 & 2 & 1 \\
\hline
\end{tabular}

\begin{tabular}{||l|l|c|}
\hline & Unacceptable & $18-36$ \\
\hline & Undesirable & $10-16$ \\
\hline \hline & Acceptable with controls & $5-9$ \\
\hline \hline & Acceptable & $1-4$ \\
\hline
\end{tabular}

Figure 2. Shows a matrix between severity and probability. 


\subsection{Layers of Protection (LOPA)}

The Layer of Protection Analysis (LOPA) method is a Process Hazard Analysis tool. The method utilizes the hazardous events, event severity, initiating causes and initiating likelihood data developed during the Hazard and Operability analysis (HAZOP) [9].

The LOPA method allows the user to determine the risk associated with the various hazardous events by utilizing their severity and the likelihood of the events being initiated. Using corporate risk standards, the user can determine the total amount of risk reduction required and analyze the risk reduction that can be achieved from various layers of protection. If additional risk reduction is required after the reduction provided by process design, the basic process control system (BPCS), alarms and associated operator actions, pressure relief valves, etc., a Safety Instrumented Function (SIF) may be required. The safety integrity level (SIL) of the SIF [10] can be determined directly from the additional risk reduction required.

\subsubsection{LOPA Advantages \& Disadvantages [11]}

\begin{tabular}{|c|c|}
\hline Disadvantage & Advantages \\
\hline a) LOPA is not a tool for identifying hazards. & a) LOPA is effective in resolving disagreements related to risk. \\
\hline b) LOPA may be excessive for simple or low risk decisions. & $\begin{array}{l}\text { b) LOPA determines whether SIS or alternative means of } \\
\text { protection are required and associated SIL if SIS is chosen. }\end{array}$ \\
\hline c) LOPA may be overly simplistic for very complex systems. & c) LOPA complies with IEC 61511, clauses 8 and 9. \\
\hline $\begin{array}{l}\text { d) Risk comparison scenarios are only valid } \\
\text { if same LOPA method is used throughout. }\end{array}$ & d) LOPA eliminates excess recommendation generation. \\
\hline
\end{tabular}

\section{Node Description}

The gas is fed to a High pressure propane cooler to decrease it's temperature. After that the stream goes to a Medium Pressure propane cooler where it's temperature is further decreased, after that part of the stream changes into liquid due to temperature decrease, Then directed to a scrub column-1, where gas is separated from liquid, by washing it with a stream of NGL, then directed to scrub column-2 to get rid of remaining heavy components, it's temperature then is nearly 35 degree Celsius (Figure 3).

\subsection{HAZOP \& DMRA Table for the Node}

\begin{tabular}{|c|c|c|c|c|c|}
\hline $\begin{array}{l}\text { Guide } \\
\text { word }\end{array}$ & Deviation & Cause & Consequence & Safeguards & DMRA \\
\hline No/less & 1) No/less flow & $\begin{array}{l}\text { 1.1 Water entry with gas } \\
1.2 \text { 15-ESDV-1196 } \\
\text { "-(emergency shutdown } \\
\text { valve) at beginning of } \\
\text { node” } \\
\text { Malfunction, partially or } \\
\text { completely close } \\
\text { 1.3 Valve pre MCHE } \\
\text { (Main Cryogenic Heat } \\
\text { Exchanger) closes }\end{array}$ & $\begin{array}{l}\text { 1.1.1 Water freezes and } \\
\text { forms ice \& hydrates on } \\
\text { tube side causing less flow } \\
\text { 1.2.1 Less flow } \\
\text { "production" } \\
\text { 1.3.1 Less flow } \\
\text { "production" }\end{array}$ & $\begin{array}{l}\text { 1.1.1.1 Inject dehydration } \\
\text { liquid to prevent } \\
\text { hydrate formation } \\
\text { 1.2/3. 1.1 Bypass \& } \\
\text { maintenance applied }\end{array}$ & $\begin{array}{c}\text { Probability }=3 \\
\text { Severity }=3 \\
\text { Risk factor }=P \times S=9 \\
\text { Type }=\text { acceptable with } \\
\text { controls }\end{array}$ \\
\hline More & 1) More flow & $\begin{array}{l}\text { 1.1 Low/medium/high } \\
\text { pressure exchangers } \\
\text { ruptured } \\
\text { 1.2 Level controller on } \\
\text { scrub column reads high } \\
\text { level and malfunction } \\
\text { open valve to drain liquid } \\
1.3 \text { Pressure release valve } \\
\text { between scrub columns } \\
\text { fails to open, and by pass } \\
\text { blocked }\end{array}$ & $\begin{array}{l}\text { 1.1.1 Causing propane } \\
\text { system to merge } \\
\text { with the NG stream } \\
\text { 1.2.1 NG will come out } \\
\text { from bottom of scrub } \\
\text { tower with liquid causing } \\
\text { hammering in pipes } \\
\text { 1.3.1 Product loss }\end{array}$ & $\begin{array}{l}\text { 1.1.1.1 Stopping propane } \\
\text { cycle, \& directing NG to } \\
\text { bypass the ruptured } \\
\text { exchanger } \\
\text { 1.2.1.1 Adding a trip for the } \\
\text { gas and alarm for gas entry } \\
\text { 1.3.1.1 Maintenance on the } \\
\text { cause of more flow }\end{array}$ & $\begin{array}{c}\text { Probability }=4 \\
\text { Severity }=3 \\
\text { Risk factor }=P \times S=12 \\
\text { Type }=\text { undesirable }\end{array}$ \\
\hline
\end{tabular}




\begin{tabular}{|c|c|c|c|c|c|}
\hline $\begin{array}{l}\text { Guide } \\
\text { word }\end{array}$ & Deviation & Cause & Consequence & Safeguard & DMRA \\
\hline Less & 1) Pressure less & 1.1 No upstream for the units & 1.1.1 No production & $\begin{array}{c}\text { Low pressure alarm } \\
\text { at beginning } \\
\text { of the Node }\end{array}$ & $\begin{array}{c}\text { Probability }=5 \\
\text { Severity }=1 \\
\text { Risk factor }=P \times S=5 \\
\text { Type }=\text { acceptable with } \\
\text { controls }\end{array}$ \\
\hline More & 1) More pressure & $\begin{array}{l}\text { 1.1 Reduction of cross section } \\
\text { of the piping, in which } \\
\text { gas passes, through due } \\
\text { to hydrate formation } \\
1.2 \text { Increase in temperature }\end{array}$ & $\begin{array}{l}\text { 1.1.1/2 Cause poisoning } \\
\text { and pollution, } \\
\text { due to release of gas } \\
\text { into the air, may cause } \\
\text { explosive mixture } \\
\text { by mixing with air }\end{array}$ & $\begin{array}{c}\text { 1.1.1.1 High pressure } \\
\text { alarm at beginning } \\
\text { of each unit }\end{array}$ & $\begin{array}{c}\text { Probability }=3 \\
\text { Severity }=5 \\
\text { Risk factor }=P \times S=15 \\
\text { Type }=\text { undesirable }\end{array}$ \\
\hline
\end{tabular}

\begin{tabular}{|c|c|c|c|c|c|}
\hline $\begin{array}{l}\text { Guide } \\
\text { word }\end{array}$ & Deviation & Cause & Consequence & Safeguard & DMRA \\
\hline Less & 1) Level & $\begin{array}{l}\text { 1) LIC (liquid indicator } \\
\text { controller)in the scrub } \\
\text { tower fails to open, } \\
\text { causing liquid drainage }\end{array}$ & $\begin{array}{l}\text { 1.1.1 Which may cause } \\
\text { gas to flow through } \\
\text { the bottom exit to unit } \\
7 \text { causing hammering }\end{array}$ & $\begin{array}{l}\text { A low level trip } \\
\text { at the scrub tower to } \\
\text { prevent gas entering }\end{array}$ & $\begin{array}{c}\text { Probability }=4 \\
\text { Severity }=3 \\
\text { Risk factor }=P \times S=12 \\
\text { Type }=\text { undesirable }\end{array}$ \\
\hline More & 1) Level & $\begin{array}{l}\text { 1.1. Malfunction of } \\
\text { flow } \\
\text { valve at bottom } \\
\text { of scrubber }\end{array}$ & $\begin{array}{l}\text { 1.1.1 Carry over at the } \\
\text { scrubber as the gas flow } \\
\text { would carry liquid with it, } \\
\text { liquid may freeze with the } \\
\text { low temperature causing dry } \\
\text { ice on inner tubes causing } \\
\text { lower production \&corrosion }\end{array}$ & $\begin{array}{l}\text { High alarm level } \\
\text { at the scrubber }\end{array}$ & $\begin{array}{c}\text { Probability }=4 \\
\text { Severity }=2 \\
\text { Risk factor }=P \times S=8 \\
\text { Type = acceptable with controls }\end{array}$ \\
\hline Change & $\begin{array}{c}\text { Composition } \\
\text { change }\end{array}$ & $\begin{array}{l}\text { 1.1. Loss of reflux } \\
\text { in the scrubber }\end{array}$ & $\begin{array}{l}\text { 1.1.1 Heavy ends directed } \\
\text { to MCHE-Main Cryogenic } \\
\text { Heat Exchanger-, causing } \\
\text { corrosion \& freezing }\end{array}$ & $\begin{array}{l}\text { Low reflux } \\
\text { alarm at entry } \\
\text { of scrub column }\end{array}$ & $\begin{array}{c}\text { Probability }=3 \\
\text { Severity }=2 \\
\text { Risk factor }=P \times S=6 \\
\text { Type = acceptable with controls }\end{array}$ \\
\hline
\end{tabular}

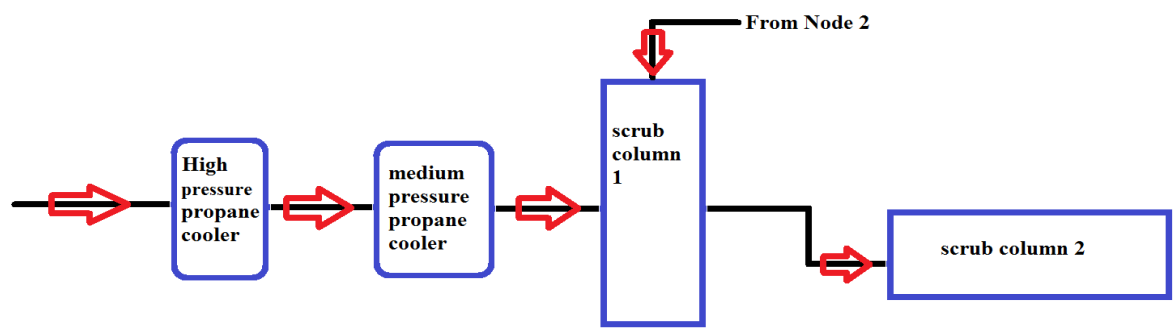

Node 1

Figure 3. PFD of the coolant Node.

\subsection{Situation Analysis}

\section{Situation 1-less flow:}

\section{Probability}

The probability for such event to occur is moderate, so it was given the probability of 3 on the scale of 6 , as there are some occasions that may occur like:

1) Problems in the well, like water mixing with the flow;

2) Leakage due to a random pipe line rupture;

3) Rupture or malfunction of a valve.

So that's why its probability is neither high, nor low.

\section{Severity}

For it is severity, it is also rated moderate, because if the reason is the lack of flow, then , the production will decrease, which means loss of money and is considered a minor harm-compared to endangering human life or equipment, as it causes no equipment or human loss. On the other hand if this occurs due to water breaking 
through the system, this will cause water to freeze within in units, mainly the main cryogenic heat exchanger, and it may cause corrosion or rupture of the body of the equipment, which is relatively an expensive equipment. So it is considered a medium harm, and in average, the severity of such an occasion took the number 3 out of 6 .

\section{Risk}

So for the risk of the whole occasion it is calculated from the formula RISK = PROBABILITY X SEVERITY, the obtained value is $3 \times 3=9$, which is considered "acceptable with controls". This means that such risk could be acceptable but with certain controls to minimize the severity of the occasion, these controls include:

1) Immediate cleaning of the pipe and equipments harmed from ice formation;

2) Bypassing and replacing the harmed valve;

3) Bypassing the ruptured pipe and immediate maintenance of the ruptured line.

\section{Situation 2-More flow}

\section{Probability}

The probability for such event to occur is moderate, as there are number of reasons that may lead to such an occasion, so it was given 4 on the scale of 6 , like:

1) Propane gas entering with main stream, due to rupture within the exchangers;

2) Fail of pressure release valve to open so flow remains high.

That's why probability is slightly higher than average, due to the numerous release valves, and increasing probability of its blockage.

\section{Severity:}

For the severity, it is rated at the scale of 3 out of 6 , as consequences that may occur:

1) Change of composition as the propane would mix with main stream, giving undesired product;

2) May cause freezing in the MCHE, also more flow may cause whether carry over from scrub column;

3) Causing flow to come from bottom outlet, causing hammering to the pumps, which are all considered minor damage to the equipment or production loss, so, it's severity was estimated by 3 .

\section{Risk}

For the risk of the situation, it is calculated from the formula RISK = PROBABILITY X SEVERITY, so the obtained value is 12 , which is undesirable. This is due to the harm to several machines, which would take long time to recover. Also, piping rupture would stop the whole process for a long time for maintenance and repair. Also this will lead to refilling of the propane cycle which means extra costs.

\section{Situation 3-Less pressure}

\section{Probability}

For the probability of this to occur is somehow high due to various reasons that may cause lower pressure, it might be caused by:

1) Problems in the well like the Gas holding capacity decreases down to a lower value;

2) Due to a rupture in the pipe line in the upstream or downstream which may cause leakage, or;

3) Any unit attached on the pipeline may have ruptured or leaked.

So it's probability is relatively high. That's why it was given the value of 5 on a scale of 6 .

\section{Severity}

For the severity of such an occasion, It is very low, as the maximum damage that might occur is the loss of production. It won't cause any damage to any unit or person, so that why it was given a value of 1 on the scale of 6 .

Risk

For the risk of such an occasion, it is calculated from the formula RISK $=$ PROBABILITY $\times$ SEVERITY, and is equal to $5 \times 1=5$ which is considered acceptable with controls. This means that such a risk could be accepted, as no serious damage to equipment or person will occur, but still with control as the loss production cannot be suspended for a long time, or a serious financial loss would occur.

\section{Situation 4-pressure increase}

\section{Probability}

The probability for such occasion to occur, is somehow high, so it was given the value of 3 on the scale of 6 , as it may caused by several reasons, like

1) Partial or total blockage of the piping;

2) Also due to increase of temperature, that will cause increase in pressure.

It was not given a higher value, because the flare is supposed to deal with over pressured stream. 


\section{Severity}

For the severity, the spreading of Natural Gas may cause headache or dizziness to nearby workers or habitants, before it is diluted in the open atmosphere. Besides, if pressure accumulated on a certain point among the pipe line it may cause explosion to nearby workers, and an explosive mixture due to mixing with air. That's why it was given the value of 5, which is somehow considered critical and causes harm-not fatal harm-to several workers or nearby inhabitants.

Risk

For the risk of such an occasion to occur, it is calculated from the formula RISK $=$ PROBABILITY $\times$ SEVERITY, which is equal to $3 \times 5=15$. This is considered undesirable, as safety of workers and inhabitants are of prime importance, and if such a mixture from the relief was exposed to spark an explosion may occur. Although there is a small probability for this to occur, as the design of the plant, is to make the relief valves far away from the flare, and in the opposite direction of the wind, so as no contact is possible, and the gas would disperse in the air before it comes in contact with any other flare around, but still it is an existing possibility.

\section{Situation 5-more temperature}

\section{Probability}

The probability for this occasion to happen is somehow lower than average, as it may be caused by problems in the propane cooling system. This may occur within a problem that happened in the propane cycle, like leakage, change in it's pressure or low efficiency in the propane refrigeration cycle... So it was given the value of 3 on the scale of 6 . As all these probabilities are somehow low and only in one part of the whole process.

\section{Severity}

For the severity for this occasion, what may occur from such a case is a minor harm to the equipment, as higher temperature, will cause less separation between gas and liquid, which will cause heavier content to be carried to the Main Cryogenic Heat Exchanger. This will cause formation of hydrates within the body of the Main Cryogenic Heat Exchanger, that may cause harm to it's body, that's why it was given the value of 3 on the scale of 6.

Risk

For the Risk of such occasion, it is calculated from the formula RISK $=$ PROBABILITY $\times$ SEVERITY, which is equal to $3 \times 3=9$, which is considered acceptable with controls, as such an occasion might be acceptable, under controls of certain maintenance of the propane cooling cycle and to the MCHE body to get rid of the hydrates.

\section{Situation 6-Low Level}

\section{Probability}

For the probability of the occasion, it is relatively high, as there are many reasons that may cause the low level in the scrubber:

1) The change of composition of the main stream, to contain less heavy content;

2) The high temperature of the stream which will cause poor separation leading to less liquid level;

3) Malfunction of the lower valve of the scrubber to fail open, causing liquid to drain.

All these are occasions that have a high probability to occur. That is why it was given the value of 4 on the scale of 6 .

\section{Severity}

For the severity of the occasion, the maximum that could happen is causing hammering in the sucking pump, that may cause damage to its body, but as it will be the only item to be harmed, and still not a serious or certain harm, it was given the value of 3 on the scale of 6 .

\section{Risk}

For the Risk of such occasion it is calculated from the formula RISK $=$ PROBABILITY $\times$ SEVERITY, which is equal to $3 \times 5=15$ which is considered undesirable, as such an occasion may stop the process to recover liquid in the scrubber and to evacuate the line between the scrubber and the pump, so will lead to a financial loss.

\section{Situation 7-High level}

\section{Probability}

The probability for such an occasion to occur is slightly higher than average, as the valves are one of the most equipments that are prone to malfunction, so it was given the value of 4 on the scale of 6 . Although the only probability for this to occur is by the malfunction of the valve, but it is still a high probability.

\section{Severity}


For the severity for such an occasion, it isn't that serious, as the carried over liquid will be frozen at the MCHE (Main cryogenic Heat Exchanger) and transformed into solid hydrates. This will require stop of process but may cause minimum damage to the equipment, so it was given the value of 2 on the scale of 6 .

\section{Risk}

For the risk of such an occasion, it is calculated from the formula RISK $=$ PROBABILITY $\times$ SEVERITY, which is equal to $4 \times 2=8$, which is considered "acceptable with controls" which means that such a risk could be handled, but it must be kept in mind that we will have to stop the process to clean up the Main Cryogenic Heat Exchanger, which means financial loss, and the repetition of such an event may cause damage to the equipment by time

\section{Situation 8-Composition Change}

\section{Probability}

The probability for such an occasion to occur is slightly less than average, as this may occur at the scrubber if loss of reflux happens. This will lead to poor separation of the liquids from the gas stream. This might happen because of the change in pressure or temperature of the main stream or the washing stream, or might happen if the composition of the main stream changes, for example if the heavy components decrease. This will cause less reflux stream-which comes from the separated heavy ends-which will cause a poor separation. All these cases have a reasonable probability for the composition to change, that's why it was given the value of 3 on the scale of 6.

\section{Severity}

For the severity for such an occasion, this will lead to the formation of hydrates on the body of the Main Cryogenic heat Exchanger. Since that is considered a minor harm as it won't cause rupture or damage from the first time, and only to one equipment, it took the value of 2 on the scale of 6 .

\section{Risk}

For the risk of such an occasion, it is calculated from the formula RISK $=$ PROBABILITY $\times$ SEVERITY, which is equal to $3 \times 2=6$, which is considered "acceptable with controls". That means that such a risk is acceptable but only with controls that prevent repeating it and also by quickly reacting to the consequences, by stopping the process and dealing with the hydrates by getting rid of them and cleaning the internal of the Main Cryogenic Heat Exchanger.

\section{Conclusions for HAZOP \& DMRA analysis:}

For Node 1, there are varieties on the scale of risk that may happen due to different occasions but we can conclude that we have four main categories in which any occasion can occur "acceptable, acceptable with controls, undesirable and unacceptable”. By categorizing the risks fir Node (1) we can find that we have the following list:

\section{1) unacceptable:}

Nil.

\section{2) undesirable:}

More pressure.

More flow.

Low level.

\section{3) acceptable with controls}

Less flow.

Less pressure.

More temperature.

Composition change.

\section{4) Acceptable}

Nil.

\section{From this categorizing we can conclude that:}

1) There is neither an acceptable nor unacceptable risk in this Node, but most risks fall between the category of undesirable and acceptable with controls.

2) We also can conclude that relatively the most risky events that can occur are the increase of pressure and flow and the reduction of liquid level in the scrubber, all of these will cause harm to the equipments and stopping the process for maintenance.

3) We also conclude that there are nearly no harm can occur to personnel within this Node. 


\subsection{LOPA Analysis}

Comment 1. The merging of the cooling propane system with the Main stream may cause further problem in the process like formation of Hydrates among the MCHE, this may be caused by the rupture of the pipes within the exchanger it self, so the streams will mix with each other, the probability of such an event is 1 over 10 , which is such a high probability, to decrease it there are several layers of protection to be added, all with percentage of its PFD. The target likelihood is to be decreased to $1 / 1,000,000$, by multiplication of the likelihood of the cause of the event and the PFD of the protection layers, we get a better result of $1 / 10,000,000$ so the IPL system is a success.

\begin{tabular}{|c|c|c|c|c|c|}
\hline \multirow{3}{*}{$\begin{array}{c}\text { Event \& target } \\
\text { likelihood } \\
\text { Merging of propane } \\
\text { stream with Natural } \\
\text { Gas main stream, } \\
\text { causing solidification } \\
\text { of flow in MCHE }\end{array}$} & \multirow{3}{*}{$\begin{array}{c}\text { Cause \& } \\
\text { likelihood } \\
\text { Tube rupture } \\
\text { inside the } \\
\text { heat exchangers }\end{array}$} & \multicolumn{3}{|c|}{$\begin{array}{l}\text { IPL (Integrated Protection Layers) } \\
\text { and its PFD (Process Failure On Demand) }\end{array}$} & \multirow[t]{3}{*}{$\begin{array}{l}\text { Mitigated } \\
\text { likelihood }\end{array}$} \\
\hline & & Process design & Alarms & SIS (PLC) & \\
\hline & & $\begin{array}{l}\text { Design the pipes } \\
\text { to hold pressure } \\
\text { much higher than } \\
\text { that of the process }\end{array}$ & $\begin{array}{l}\text { An alarm should be } \\
\text { present to detect } \\
\text { whether the composition } \\
\text { changed of the Main } \\
\text { stream, if so operator } \\
\text { should stop process } \\
\text { immediately }\end{array}$ & $\begin{array}{l}\text { Logic in PLC once } \\
\text { a composition change } \\
\text { detected, shuts the } \\
\text { propane cycle and } \\
\text { directs part of main } \\
\text { stream to the flare }\end{array}$ & \\
\hline $1 \mathrm{E}-6$ & I.E-1 & $1 E-2$ & $1 E-1$ & $1 E-3$ & \\
\hline
\end{tabular}

Comment 2. The event is the carryover of the liquid from the upper opening with the gas, this will cause the formation of hydrates within the cooling equipment-MCHE, this may happen with a relatively high probability, as the MCHE is an extensive equipment, and hydrate formation may cause its damage. Several layers of protection would be applied to decrease the likelihood of such an event this includes (Human action, Alarms, SIS (PLC)) this would decrease the probability of occurring of these events to an acceptable rate from $1 / 100$ to $2.6 / 10,000,000$, while the acceptable limit is $1 / 100,000$. So the IPL system is a success.

\begin{tabular}{|c|c|c|c|c|c|}
\hline \multirow{2}{*}{$\begin{array}{l}\text { Event \& target } \\
\text { likelihood } \\
\text { Gas coming out } \\
\text { from bottom } \\
\text { opening with the } \\
\text { liquid, this might } \\
\text { cause hammering } \\
\text { and damage } \\
\text { to the pump }\end{array}$} & \multirow{2}{*}{$\begin{array}{c}\text { Cause \& } \\
\text { likelihood } \\
\text { Fail of the sensor } \\
\text { to read low level, } \\
\text { or fail of the pump } \\
\text { at the bottom to } \\
\text { stop draining } \\
\text { liquids } \\
\text { (sealing failure) }\end{array}$} & \multicolumn{3}{|c|}{$\begin{array}{l}\text { IPL (Integrated Protection Layers) } \\
\text { and its PFD (Process Failure on Demand) }\end{array}$} & \multirow[t]{2}{*}{$\begin{array}{l}\text { Mitigated } \\
\text { likelihood }\end{array}$} \\
\hline & & $\begin{array}{l}\text { Human response } \\
\text { to the alarm and } \\
\text { manually close } \\
\text { the valve }\end{array}$ & $\begin{array}{l}\text { A noticeable } \\
\text { Alarm that would } \\
\text { start if the level } \\
\text { keeps decreasing } \\
\text { after the sensor's } \\
\text { read within a few } \\
\text { minutes }\end{array}$ & $\begin{array}{l}\text { Logic in PLC once a } \\
\text { change in the Gas flow } \\
\text { rate detected after the } \\
\text { scrubber with a reasonable } \\
\text { amount, the pump would } \\
\text { be shutdown and the pipe } \\
\text { after the pump sealed }\end{array}$ & \\
\hline $1 E-5$ & $1 \mathrm{E}-1$ & $1 \mathrm{E}-1$ & $2.6 \mathrm{E}-1$ & $1 E-3$ & \\
\hline
\end{tabular}

Comment 3. The scrub tower has an upper opening for gas exit and bottom opening for liquid exit, incase the liquid level fails below safe point, gas might come out from bottom opening and then it would be sucked by the bottom pump, for air to be sucked by the pump this would cause hammering and damage for the pump. This has relatively high probability to occur. To decrease the probability for such an event, several layers of protection would be added to decrease occurrence of the event. The layers of protections are (Human Action-Alarms-SIS (PLC)). The occurrence of the event is $1 / 10$, and the target is to decrease it to $1 / 100,000$, the layers of protection decreased it to $2.6 / 10,000,000$, so the system was a success.

\begin{tabular}{|c|c|c|c|c|c|}
\hline \multirow{2}{*}{$\begin{array}{l}\text { Event \& target } \\
\text { likelihood } \\
\text { Liquid carried over } \\
\text { from the top of the } \\
\text { scrub tower by the } \\
\text { gas causing } \\
\text { hydrate formation }\end{array}$} & \multirow{2}{*}{$\begin{array}{c}\text { Cause \& } \\
\text { likelihood } \\
\text { Fail of the sensor } \\
\text { to read high level, or } \\
\text { fail of the valve } \\
\text { at bottom of the } \\
\text { tower to open } \\
\text { to drain liquid }\end{array}$} & \multicolumn{3}{|c|}{$\begin{array}{l}\text { IPL (Integrated Protection Layers) } \\
\text { and its PFD (Process Failure on Demand) }\end{array}$} & $\begin{array}{l}\text { Mitigated } \\
\text { likelihood }\end{array}$ \\
\hline & & $\begin{array}{l}\text { Human action } \\
\text { Human response } \\
\text { to the alarm } \\
\text { and manually } \\
\text { open the valve }\end{array}$ & $\begin{array}{l}\text { A noticeable Alarm } \\
\text { that would start if } \\
\text { the level did not } \\
\text { decrease after the } \\
\text { sensor's read } \\
\text { within a few } \\
\text { minutes }\end{array}$ & $\begin{array}{l}\text { Logic in PLC once a change } \\
\text { in the liquid composition } \\
\text { detected after the scrubber } \\
\text { with a reasonable amount, } \\
\text { automatically MCHE } \\
\text { would be pay passed } \\
\text { to prevent Hydrate formation. }\end{array}$ & $2.6 \mathrm{E}-7$ \\
\hline $1 \mathrm{E}-5$ & $1 \mathrm{E}-2$ & $1 \mathrm{E}-1$ & $2.6 \mathrm{E}-1$ & $1 E-3$ & \\
\hline
\end{tabular}


Comment 4. One of the reasons that may cause production loss is the fail of the Pressure Release Valve to open or its rupture, this will cause production loss, the production stop to over come this effect. The probability of this event is relatively high. To decrease the probability of this cause, several layers of protection are applied to decrease the probability of this cause to occur which are (Human Action-Alarms-SIS (PLC)-Design). The target of this event is to reach a 1/1,000,000 probability, while the layers succeeded to make the probability decrease to $2.6 / 1,000,000,000$. So this Layers of protection system is a success.

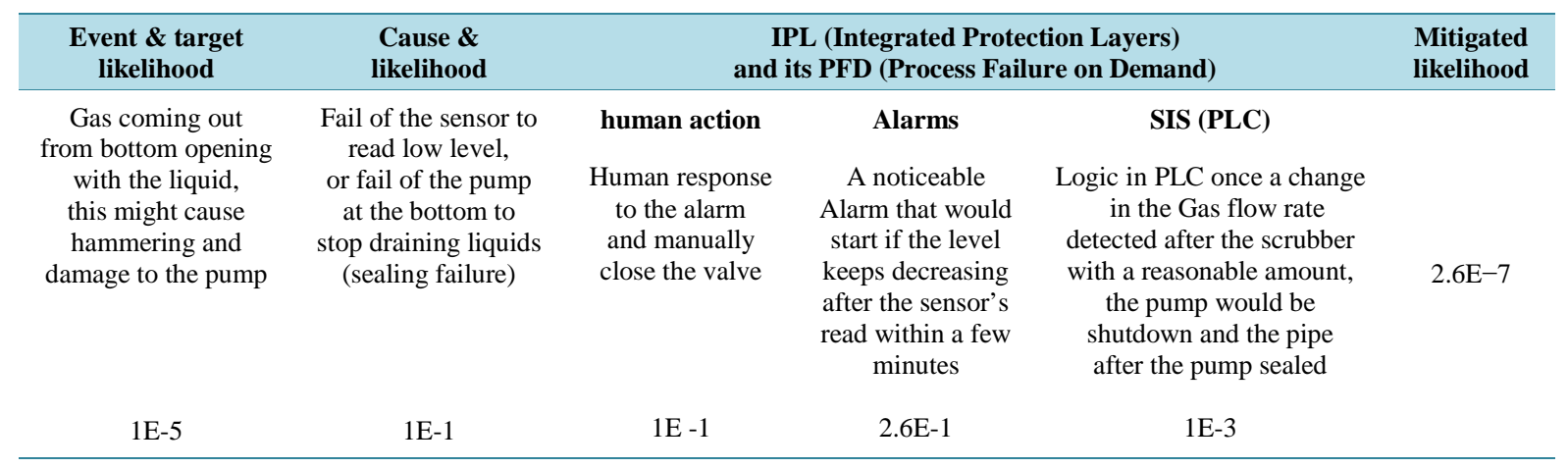

Comment 5. The cooling is used to condensate the heavy liquids in the scrub tower, incase the cooling cycle is inefficient, the condensate will not be efficient and heavy liquids would be carried to the MCHE causing hydrate formation and its damage. The most probable reason for this happen is leakage in the propane cycle. To decrease the probability of this reason to occur, several protection layers are applied, the target of this event is to decrease its probability to $1 / 1,000,000$, the protection layers (Human Action-Design-SIS(PLC)-Alarms) succeeded to decrease the probability of the event to $2.6 / 1000,000,000$. So the safety system of protection layer is a success.

\begin{tabular}{|c|c|c|c|c|c|c|}
\hline \multirow{2}{*}{$\begin{array}{c}\text { Event \& target } \\
\text { likelihood } \\
\text { Pressure } \\
\text { release valve } \\
\text { between scrub } \\
\text { tower fails to } \\
\text { open causing } \\
\text { product loss }\end{array}$} & \multirow{2}{*}{$\begin{array}{c}\text { Cause \& } \\
\text { likelihood } \\
\text { Pressure } \\
\text { Release vale } \\
\text { malfunctions } \\
\text { and fails } \\
\text { to open }\end{array}$} & \multicolumn{4}{|c|}{$\begin{array}{l}\text { IPL (Integrated Protection Layers) } \\
\text { and its PFD (Process Failure on Demand) }\end{array}$} & \multirow[t]{2}{*}{$\begin{array}{l}\text { Mitigated } \\
\text { likelihood }\end{array}$} \\
\hline & & $\begin{array}{l}\text { Human action } \\
\text { Human response } \\
\text { to the alarm and } \\
\text { manually close the } \\
\text { valve before the } \\
\text { pressure release } \\
\text { valve }\end{array}$ & $\begin{array}{c}\text { A noticeable } \\
\text { Alarm that } \\
\text { would start if } \\
\text { the flow rate } \\
\text { kept low for a few } \\
\text { minutes }\end{array}$ & $\begin{array}{l}\text { Logic in PLC once a } \\
\text { a change in the Gas } \\
\text { flow rate detected } \\
\text { after the scrubber } \\
\text { with a reasonable } \\
\text { amount, a bypass } \\
\text { for the scrubbing } \\
\text { would occur and flow } \\
\text { redirected to flare }\end{array}$ & $\begin{array}{c}\text { A manual valve } \\
\text { would be added } \\
\text { before the pressure } \\
\text { release valve }\end{array}$ & \\
\hline $1 E-6$ & $1 E-2$ & $1 \mathrm{E}-1$ & $2.6 \mathrm{E}-1$ & $1 E-3$ & $1 E-2$ & \\
\hline
\end{tabular}

\section{Acknowledgements}

I would like to thank everyone who helped me to prepare this paper. I would mention specially Dr. Hassan Farag who aided me from the beginning of the preparation step by step. Moreover, I would like to thank Dr. Moustafa Salem for his non stoppable efforts to me through my period of writing the letter and even before.

\section{References}

[1] National Academy of Sciences, 1976.

[2] An Overview on Liquefied Natural Gas (LNG), Its Properties, the LNG Industry and Safety Considerations.

[3] Woodward, J.L. and Pitblado, R.M. LNG Risk Based Safety Modeling and Consequence Analysis.

[4] Curacao Cng-Lng Terminal Feasibility Study.

[5] Zhang Wei, Wu Zhang. Distributed \& Embedded Systems Lab Lanzhou University, Lanzhou.

[6] HAZOP Pros and Cons_-by David Gossman.

[7] Marhavilas, P.K., Koulouriotis, D. and Gemeni, V. (2011) Risk Analysis and Assessment Methodologies in the Work Sites: On a Review, Classification and Comparative Study of the Scientific Literature of the Period 2000-2009. Journal of Loss Prevention in the Process Industries, 24, 477-523 
[8] Saudi Aramco HAZOP Guide Lines.

[9] 1997 CCPS Conference and Workshop Proceedings Layer of Protection Analysis: A New PHA Tool after HAZOP, before Fault Tree Analysis.

[10] Dowell, A.M. (1999) Layer of Protection Analysis and Inherently Safer Process. Process Safety Progress, 18, $214-220$. http://dx.doi.org/10.1002/prs.680180409

[11] Summers, A.E. (2003) Introduction to Layer of Protection Analysis. Journal of Hazardous Materials, 104, $163-168$. http://dx.doi.org/10.1016/S0304-3894(03)00242-5 